\section{DIGITAL COMMONS \\ @ UNIVERSITY OF SOUTH FLORIDA}

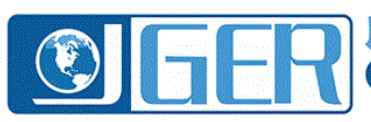

Journal of

Global Education and Research

June 2022

\title{
Self-segregation, sense of belonging, and social support: An inquiry into the practices and perceptions of Chinese graduate students at an American Mid-Atlantic University
}

\author{
P. J. Moore-Jones \\ George Mason University, pmoore18@gmu.edu
}

Follow this and additional works at: https://digitalcommons.usf.edu/jger

Part of the Bilingual, Multilingual, and Multicultural Education Commons, Higher Education Commons, Language and Literacy Education Commons, and the Social and Philosophical Foundations of Education

Commons

This Refereed Article is brought to you for free and open access by the M3 Center at the University of South Florida Sarasota-Manatee at Digital Commons @ University of South Florida. It has been accepted for inclusion in Journal of Global Education and Research by an authorized editor of Digital Commons @ University of South Florida. For more information, please contact digitalcommons@usf.edu.

\section{Recommended Citation}

Moore-Jones, P. (2022). Self-segregation, sense of belonging, and social support: An inquiry into the practices and perceptions of Chinese graduate students at an American Mid-Atlantic University. Journal of Global Education and Research, 6(1), 1-12. https://www.doi.org/10.5038/2577-509X.6.1.1114

Corresponding Author

P. J. Moore-Jones, 4400 University Drive, Fairfax, VA 22030, United States

\section{Revisions}

Submission date: Jun. 27, 2019; 1st Revision: Sep. 3, 2019; 2nd Revision: Feb. 25, 2020; 3rd Revision: Apr. 23, 2020;

4th Revision: Aug. 20, 2020; 5th Revision: Feb. 28, 2021; Acceptance: Mar. 29, 2021 


\title{
Self-Segregation, Sense of Belonging, and Social Support: An Inquiry Into the Practices and Perceptions of Chinese Graduate Students at an American Mid-Atlantic University
}

\author{
P. J. Moore-Jones \\ INTO Mason \\ George Mason University, United States of America \\ pmoore18@gmu.edu
}

\begin{abstract}
Chinese students studying in the United States face great challenges when adapting to cultural, linguistic, and pedagogical differences. Although discouraged in the literature, self-segregation is a practice common among some international students and is especially prevalent in the Chinese community. This qualitative study explored the motivation and frequency of this practice vis-à-vis social support, and its effect on the participants' sense of belonging. Insider status was employed to conduct focus groups of mainland Chinese students currently enrolled in graduate programs at a Mid-Atlantic University in the United States. Findings from the study explore how administrators, educators, and the students themselves view the practice of self-segregation and its consequences.
\end{abstract}

Keywords: intercultural competence, global education, international education, Chinese international students

\section{Introduction}

International education and study abroad programs have grown exponentially in the $21^{\text {st }}$ century at all levels of education. Native English-speaking countries have seen the largest growth in higher education; with China sending the greatest number of students to these institutions (Leong, 2015). Current numbers indicate there are over 330,000 Chinese higher education students in the United States and projections suggest this number will reach half a million by 2025 (Allen-Embrahimian, 2018). The experiences of these international students, and their academic performance, are affected by a myriad of variables. One of the most influential parts of the student experience is the social aspect of these students' lives abroad (Leong, 2015).

While a college student's sense of belonging has been suggested to influence academic success, it remains unclear how positively, and to what extent. Glass \& Westmont (2014) argue that crosscultural interaction and extracurricular activities nurture this sense and therefore are beneficial to college students. Others suggest these practices are distracting to students, and while the social capital gained by them is significant, academic success is not a predictive byproduct of these interactions (Coles \& Swami, 2012; Mannon, 2007). Another factor that affects both academic success and social capital is social support. Although social support is relevant in any environment, 
Journal of Global Education and Research, Vol. 6, Iss. 1 [2022], Art. 1, pp. 1- 12

this is a term used in the literature to describe all factors of interaction by the student in an educational environment (Coles \& Swami, 2012).

While there is limited research on the social practices of Chinese immigrants, Alexander et al. (1976) conducted a study more than 40 years ago that found that the Chinese were an isolated population; maintaining close relationships with only individuals from their own country. More recently, Leong (2015) noted that Asian students, in general, are at a linguistic and cultural disadvantage; and as a result, have a more arduous task in studying abroad. Rose-Redwood \& Rose-Redwood (2013) found this as well and suggested self-segregation was a solution for many of these students.

Considering the growing number of Chinese international students in the United States., more research is needed to measure the impact of the cross-cultural interaction and social engagement in the lives of these students. Specifically, what are these students' social practices and how do those practices affect their academic success? While previous studies have focused on the international student community, few researchers have explored the Chinese international student population. Thus, the purpose of this study was to examine the practices of Chinese graduate students at a Mid-Atlantic research university (MAU). It also explored if self-segregation was utilized as a practice; and if so, how it affected these students' sense of belonging within the university as well as their perceived level of social support.

\section{Review of the Literature}

As stated, the factors and variables of this study have been given a great deal of attention in the literature; however, few studies have focused on Chinese international students. The following sections review some of the findings of these factors as well as commentary as to how they can be understood through the lens of the current study.

\section{Chinese International Students}

While the number of Chinese students coming to the United States has been steadily increasing in recent decades, several studies have noted that Asian students faced more stress in their studies due to cultural, linguistic and pedagogical differences from the United States compared to their European counterparts (Behrnd \& Porzelt, 2012; Leong, 2015; Rienties et al., 2012). More specifically, one major finding from Rienties et al. (2012) was that Asian student success, or lack thereof, both socially and academically was related to the "distance in East-West social conventions among international students" (p. 696). As a result of this distance, students found it more challenging to reach desired academic outcomes (Rienties et al., 2012). To compound these issues, Heikinheimo \& Shute (1986) found over three decades ago that Chinese students showed signs of lower physical and mental health than other international students. Leong's (2015) more recent study contends this may not have changed much over the decades.

Related to these mental and health issues, Leong (2015) notes that the struggles of international Chinese students may be due to extreme amounts of culture shock in social and academic settings. A main pedagogical issue that Chinese international students face is that they "are required to take greater responsibility for their education, as they were required to work more independently" (Leong, 2015, p. 461). Peng et al. (2015) point to intercultural competence (ICC) as a central factor 
in the difficulties and stress that many of these students face. Generally, this competence has been defined as the "ability to interact, work, study, teach and live with cultures that we consider being different from our own" (Guilherme, 2004, p. 26). Hiller and Woziak (2009) suggest that ICC is connected to "tolerance for ambiguity, behavioral flexibility, communicative awareness, knowledge discovery, respect for others, and empathy" (p. 119).

The development, or lack thereof, of ICC is contingent upon the frequency of cross-cultural interactions which several studies have shown to be an uncommon practice among Chinese university students (Leong, 2015; Peng et al., 2013; Trice, 2004). Therefore, Chinese students are known to express lower levels of intercultural competence. However, this may be because ICC is difficult to measure and those who have come to such conclusions have often done so from a Western perspective (Spitzberg \& Changnon, 2009). Wu et al. (2013) offer an alternative model in this measurement which includes the factor of 'awareness in a Chinese context'. In a separate study, the same authors assert that Confucian values permeate all aspects of education and the interplay of these values with foreign cultures often create roadblocks in the development of ICC (Peng et al., 2015). These values often display a tradition of respect, courtesy and harmony without the possibility, or ability, to assimilate or conform (Peng et al., 2015).

\section{Sense of Belonging}

A significant amount of the literature on a student's sense of belonging suggests that it has great effect on their academic success (Bowmann, 2011; Glass \& Westmont, 2014; Locks et al., 2008). Thus, sense of belonging in the general student population has been studied notably in the literature. Glass \& Westmont (2014) found a sense of belonging in higher education to include a "sense of connection to their college, degree of social support, and experience of both academic challenge and support" (p. 108). Educational psychologists believe that belonging refers to a means to understand interpersonal behavior (Locks et al., 2008). In a higher education environment, this includes the extent to which students feel "part of the community" and "members of the campus community" (Locks et al., 2008, p. 260). Hurtado \& Carter (1997) argue that a sense of belonging "captures the individual's view of whether he or she feels included in the college community" (Johnson et al., 2007, p. 532). It also includes levels of enthusiasm toward the college or university as well as willingness or probability to recommend the institution to future potential students (Johnson et al., 2007).

Considering the apparent benefits of achieving a sense of belonging, previous literature has addressed the prospect of how this might be heightened or nurtured in all students' experiences (Trice, 2004). A sense of belonging as a theoretical construct in globalized higher education settings has been studied inconsistently in the literature and this concept applied to Chinese students in higher education has received little attention. While research has shown that a sense of belonging is directly correlated to academic success in domestic students, less is known about how international students develop a sense of belonging and how it effects their educational experience (Bowmann, 2011).

Pham \& Tran (2015) posit "Belongingness is among the primary factors shaping international students' well-being, success and adaptation to their host country. When a need to belong is unsatisfied, international students often experience loneliness, lower motivation and disengagement" (p. 204). The traditional notion of this assumes that some interaction with host 
Journal of Global Education and Research, Vol. 6, Iss. 1 [2022], Art. 1, pp. 1- 12

nationals is a byproduct or even has a causal relation to this sense of belonging (Glass \& Westmont, 2014). A separate notion suggests that campuses which consider themselves to actively embrace international diversity, make a purposeful effort to ensure its activities on campus produce students with a higher sense of belonging and cultural understanding (Glass \& Westmont, 2014).

Some researchers have tied together the constructs of sense of belonging and sense of community. These can be and often are separate entities whereby a student may have a strong sense of community within their own circles without having the sense of belonging to the campus or university as a whole (Berger, 1997). As we further differentiate previous literature from the data presented in this paper, this distinction becomes clearer. We see this more clearly when we examine specific groups of international students and take into the consideration their general worldviews and educational cultures.

\section{Self-Segregation in the Chinese International Student Community}

Self-segregation is defined as actively avoiding integration with other groups (Rose-Redwood \& Rose-Redwood, 2013). In the context of international education, this is often associated with nationality. This can be seen as an effect of what levels of social support are needed or desired by the international student. Self-segregation provides familiarity and comfort in unfamiliar environments. Yet, this practice not only impedes the development of ICC, but it also renders the process unnecessary (Stahl, 1998). Self-segregation is a common method of gaining social support among the Chinese international student community. However, it can impede assimilation, increase linguistic and cultural miscues, and stymie the development of corrective behaviors (Coles \& Swami, 2012; Leong, 2015). Additionally, while some researchers have found that Asian international students cite inadequate levels of social support in their daily lives (Young, 2017), data from this study contradicts these statements. As found in previous studies, social support has been found to be an important predictor in the development of a sense of belonging as well as retention in a degree program (Morrow \& Ackermann, 2012). Wilcox et al., (2005) went even further stating that social support is indicative of overall academic success.

Conventional thinking in the early stages of international education employed the idea that interaction with host nationals could mitigate the struggles that international students face linguistically and culturally. Leong (2015) examined Chinese international students social challenges in the American higher education system. A number of the participants noted that they initially expected to develop these relationships with their host nationals; yet were often disappointed as these relationships were not easily realized, if at all. Looking at how international students' sense of belongingness based on their cross-cultural interaction, Glass \& Westmont (2014) found that only $7 \%$ of their participants considered themselves host interactors which they defined as friendships or support from peers of the host country. Many of their participants cited that language and cultural barriers were significant variables as to why these connections were arduous (Glass \& Westmont, 2014). There was ample evidence in the literature that point to negative attitudes from host nationals toward international students as well as a lack of motivation to interact with them (Pham \& Tran, 2015). Often not acknowledged are the host national students' inability to speak other languages and/or interact with culturally diverse students (Pham \& Tran, 2015). Coles \& Swami (2012) found contact between the host and the international student tended to be superficial and not meaningful for fostering relationships. 
Pham \& Tran (2015) found that students studying abroad noted an inability or unwillingness to embrace relationships or interactions with host nationals which created a lack of empathy in their student experience. This void was reportedly filled by establishing relationships with co-nationals, which led to an equally advantageous sense of belonging within this community by way of sufficient social support (Pham \& Tran, 2015). Russell et al. (2010) concurred by stating, "Having a significant number of friends from the same culture can have just as positive effect on social integration and academic performance as connections from members of a host culture in similar residential or social groups" (p. 689). A growing body of literature highlights the benefits of selfsegregation noting that by restricting social interactions with co-nationals, international students increase their confidence in their own cultural identity (Rose-Redwood \& Rose-Redwood, 2013).

Consideration of empathy and social support mentioned in this literature offer a contrast to conventional thoughts on study abroad programs which cite interaction with host nationals as not only beneficial, but crucial to academic success. Trice (2004) noted that international students who interacted with Americans were better adapted than those who self-segregated, and that having strong bonds with co-nationals is an important part of social support. Therefore, it must be an integral part of any international student program.

This study sought to explore the concept of how a sense of belonging was manifested in Chinese graduate students. Additionally, it sought to understand how these seemingly opposing viewpoints revealed themselves in the globalized campus of a Mid-Atlantic research university (MAU).

\section{Methods}

This study sought to understand Chinese international students' perceptions and practices while studying abroad and explored the practices, or non-practices, of self-segregation to discover what effects it had on the students' sense of belonging. To gather rich and meaningful data, focus groups were used as opposed to a questionnaire survey (Cohen et al., 2007). This method allowed for further follow-up and probing questions where needed to clearly understand factors such as rationales for practices (Cohen et al., 2007). Participants were invited via email, in English, by the researcher. The email provided the invitees with information regarding the purpose of the research. The invitation itself informed the students of the anonymity and voluntary nature of the study, the rights of the participants, notably the right to refuse to answer any of the questions as well as the right to redact any statements given (Cohen et al., 2007).

Data were collected using a qualitative approach from 17 graduate students at a Mid-Atlantic research university after an IRB review was conducted. There were 104 invitations sent via email to individuals identified as international students from Mainland China. Students who were identified as from Taiwan, Hong Kong, Macau, or any other Chinese territories were omitted as potential participants. Invitees were also provided with the list of the interview questions. Of the 104 invitations sent, only 17 agreed to participate in this study. Yang et al. (1994) have noted that low response rates are common among Asian international students due to a variety of factors; most notably, perceived time constraints.

The study participants were Chinese international students pursuing a master's degree. Their length of stay in the United States ranged from two months to two years. The age range of the participants was between 22 and 28 years old. All participants had been accepted to the university 
which had entry requirements of either a 5.5 IELTS score or a 65 TOEFL iBT score. This requirement ensured a tentative level of understanding of the English language since the focus groups were conducted in English; however, minor translation of some of the questions into Mandarin was also employed in one or two instances at the request of a participant. The translation was done by the research assistant.

Participants signed up for a desired time slot and group. The semi-structured focus groups were open-ended and consisted of between two and five participants per group. As mentioned, this method of data collection allowed for deeper inquiry (Cohen et al., 2007). Each session lasted between 30 and 90 minutes, consisted of 17 question items and were conducted on campus. There were five female and 12 male participants in the focus groups.

This research employed the use of insider status in the data collection phase of the research. While the participants were aware that this research was to be conducted by myself, a Caucasian, nativeEnglish speaker of American nationality, a research assistant conducted all focus groups. The research assistant was a fellow Chinese national of the same age range as the participants. She also was a graduate student at the same MAU.

The interviews were audio recorded and transcribed by the research assistant who took field notes mostly consisting of follow-up questions. Themes were then coded by me, the researcher. Analysis was conducted by parsing out general themes regarding the research questions, noting the frequency of such results. When present, opposing viewpoints and responses were noted. The research assistant was briefed by me regarding the relevant literature and rationale for the study prior to conducting the focus groups.

\section{Results and Discussion}

The following section will present the results of the focus groups as well as a discussion and analysis of the data. It will be organized into three sections including data regarding selfsegregation, sense of belongingness, and social support. Pseudonyms were used for all participants to ensure anonymity.

\section{Data \& Discussion Regarding Self-Segregation}

All participants, except one, lived with Chinese co-nationals exclusively. Participants noted that they had arranged their living situations through various connections with other Chinese nationals including social media, family members, as well as fellow MAU students they met in previous classes and/or on campus. All noted that the language of their home was Chinese exclusively, save for discussions they had regarding their courses' subject matter which was in English. There was one exception to this, which was a single participant who had a roommate from Thailand with whom he spoke English.

When asked why the decision was made to live with co-nationals, a variety of responses were given, yet some adhered to common themes.

It's just easier to live with Chinese. We eat the same food and understand each other better. I have so many [sic] to deal with here in America in my studies, in my life. When I come home, I don't want that pressure (Benxi, $2^{\text {nd }}$ year graduate student). 
I found a house near campus with all Chinese people it in. It's very convenient for me there. If I need help with anything, there is always someone at home who can help me. Sometimes, I don't even know how to ask what I need to ask in English so getting help is very easy for me (Xiaofeng, $1^{\text {st }}$ year graduate student).

The practice of self-segregation had been previously noted in the literature regarding Chinese students studying abroad (Leong, 2012; Peng et al., 2015). Certain familiarities can provide a sense of comfort and assurance to anyone placed in a diverse and/or intercultural context. However, the fact that 16 out of the 17 participants lived with co-nationals only, some of whom were into their second or third year of residence in the United States, shows an extreme adherence to the practice.

In addition to in living situations, self-segregation also permeated much of the social lives of the participants. The response by participant Leming was consistent with responses from other participants.

I know other international students through my classes but rarely spend time with them outside of class. The Americans I've met are very difficult to connect with. All of my friends are Chinese. We speak Chinese together, enjoy Chinese movies, TV and food together. Just everything. Sure, I live in America but really, I reside in my own country's community (Leming, $2^{\text {nd }}$ year graduate student).

Reponses such as this were not unexpected. However, the literature states that interaction with host nationals is vitally important to linguistic development and academic success. It was unknown if this particular participant was aware of this. Therefore, further exploration was attempted to learn to what extent this interaction occurred (Coles \& Swami, 2012; Glass \& Westmont, 2014; RoseRedwood \& Rose-Redwood, 2013; Trice, 2004). The following responses were representative of most participants' attitudes and practices, or non-practices, of interaction with American host nationals.

I want to talk with Americans, but I have no confidence in my English. When I speak with native-English speakers, sometimes I can't understand them and it's very embarrassing. I never talk to them, just the Chinese in my classes. But when I do talk to Americans, I cannot answer deeply, just ask simple questions, answers and so on (Yuhan, $1^{\text {st }}$ year graduate student).

I have the chance [to speak with Americans] every day. But I don't make any effort. I came for a degree and when I am done, I will go back to China. I came to study, not to make friends. I have no bad experience with this, but I also have no interest. It is meaningless ( $\mathrm{Xi}, 3^{\text {rd }}$ year graduate student).

Americans don't really want to talk to me. I figured it must be the language barrier but it's cultural too. It's like they don't know what to talk about. I used to try but kind of gave up. It's like, there may be a misunderstanding and instead of working on it, we both kind of give up. This makes being friendly very hard to do for both of us. When they just see me, they don't know I am not from here but when I start to talk, they can hear that I am real Chinese and suddenly, they stop making eye contact with me and give up. The first year, I tried to become, you know, one of them. Then I realized that's impossible (Jian Hong, $3^{\text {rd }}$ year graduate student).

Previous findings have suggested that American students, especially young Americans often lack the intercultural competence or even exposure to embrace international diversity on college campuses (Johnson et al., 2007). This coupled with Peng et al.'s (2015) findings that Chinese students also lack cross-cultural awareness, supports this study's findings that participants struggled to relate to their American classmates. However, there are multiple separate factors that might affect these Chinese students' educational experiences. 
Journal of Global Education and Research, Vol. 6, Iss. 1 [2022], Art. 1, pp. 1- 12

MAU has a very diverse student population; not only racially but also ethnically. The number of international students exceeds many of the neighboring Research-1 institutions of higher education. Therefore, this study examined what the participants' attitudes and practices of interaction were regarding other international students. A variety of responses were given.

\begin{abstract}
Sometimes we can [interact] and maybe we will be friends, because we are in the same situation and we know what we want. So, it's easier to get to know international students than Americans. I feel like you are allowed to make mistakes with them (Tzu Yu, $1^{\text {st }}$ year graduate student).

I don't think it's important [to interact with international students]. I can't understand them either and sometimes, I just learn their mistakes. There are a lot of Indians here, I can't understand them. They talk too fast (Benxi, $2^{\text {nd }}$ year graduate student).

Our department gives lots of chances to meet other international students. There's no stress with them. I can just talk and not worry if I am correct. So far, it's been good, and I've made some friends from Korea, Thailand, Japan. I like these people but I'm still not very good at this ( $\mathrm{Yu}, 1^{\text {st }}$ year graduate student).
\end{abstract}

\title{
Data and Discussion Regarding Social Support
}

These data begin to suggest much of the practice of self-segregation could be due to culture, language, familiarity, and general ease of life. Yet a significant amount of the data regarding selfsegregation relates to social support. Coming to the United States from abroad can be a daunting task in itself; even more so when coupled with the academic rigor of a graduate program. Considering this, participants of this study were questioned regarding the levels of social support they possessed and from whom these levels of support derived from.

I feel like I'm still in China, kind of. All of my friends are Chinese, I speak Chinese all day except in class. Really, class is the only time I need to speak English. We help each other a lot and share a lot of information about, everything really. Maybe I could have done this on my own, maybe not. I'm very happy to have my Chinese friends and roommates (Chexin, $2^{\text {nd }}$ year graduate student).

I know my friends will help me if I don't understand something. Usually, we leave class not really sure what the lecture was about and what to do for our assignments. Together we can be sure, someone always understood the important parts so after class we discuss everything (Benxi, $1^{\text {st }}$ year graduate student).

I study with other international students when I have to. Like, sometimes we have group projects. I dislike making the effort to talk to them though. But if I am on my own, I will find a Chinese to help me (Yu, $2^{\text {nd }}$ year graduate student).

From these responses, social support was found to be a driving factor that led to self-segregation. Participants also stated that social events and gatherings played a minor part in their lives. When questioned about the social aspects of their lives, most participants commented on how their social contacts were not only Chinese in nationality but that their conversations were mostly academic in nature. This was a unique finding as the literature claims that intercultural social events have a significant impact on the development of social support of international students.

\section{Data and Discussion Regarding Sense of Belonging}

The following data present responses from participants' reflections on their own sense of belongingness as students in the United States and members of the student community of MAU. A few caveats should be mentioned before these data are shown. Firstly, participants were not 
given working definitions of the term sense of belongingness due to a number of factors, namely that the term itself can be viewed as self-explanatory in nature; however, due to its contextual complexity, I wished to learn which context the participants would address first. As expected, some responses were related to their sense(s) of belongingness at the university and others were in response to their perceptions of living in the United States. This was by design. I wished to learn both but was particularly interested in which of these would be mentioned first as this would give insight into which was most significant to the participants.

Secondly, the responses to this line of inquiry were organized not only by the context of their answers but also by underlying cultural issues. These tended to focus on the participants' lives in the United States, academic performance, and their perceptions of their success or lack thereof within the context of MAU.

Participants had varied results in their perceived sense of belongingness.

Yes, I think I belong here, like, when I first came, I was invited to many Chinese students' houses for traditional Chinese food. We also have our own Chinese MAU student group on WeChat and we share everything on there. This makes me feel like I belong here (Xi, $3^{\text {rd }}$ year graduate student).

Maybe the reason my answer is [I have a sense of belonging here] is because I only interact with my conationals. I know I don't belong in America but I feel like I belong at [MAU] because of my Chinese friends and classmates (Ming, $2^{\text {nd }}$ year graduate student).

Sometimes the way I am treated by Americans makes me think it was a mistake to come (Mao, $1^{\text {st }}$ year graduate student).

These responses show the effects of the co-national community on the participants' perceptions. Although MAU offers events which promote this integration, participants noted that they had reason to prefer self-segregation. Participant Mao's comment demonstrates this point explicitly. Leming offered notable insight into how certain cultural normative differences manifest themselves.

In Eastern culture, we need to be humble and polite but in America, people speak up, like stand up for themselves. So, if you are humble, that means you are weak here. So, sometimes [Americans] will take advantage of that. For a long time, I didn't feel I belonged here because of this but then I learned to do things their way. Now, I have more friends, like from everywhere and my life is easier (Leming, $2^{\text {nd }}$ year graduate student).

This participant made cultural distinction a practice and altered his behavior to gain social capital. He noted this led to a positive effect for him and, in turn, his sense of belonging. Additional responses focused more on academic issues related to student life the university. This was the focus of previous research stating that sense of belonging affects academic success, therefore it was interesting to learn more about these interactions (Glass \& Westmont, 2014). In this study, the participants indicated that the cultural impacts and long-term thinking of Chinese culture might conflict with the cultural factors which might affect behavior.

It depends, if I achieve something in class, I feel like I am in the right place. This can influence my mood, motivation to study. My [Chinese] roommates help me so much with my assignments so in that way, I have a sense of belonging because of them (Benxi, $2^{\text {nd }}$ year graduate student). 
Journal of Global Education and Research, Vol. 6, Iss. 1 [2022], Art. 1, pp. 1- 12

I don't have this sense but I don't care. I am here to study, get my degree and then I will go back to China.

This is not important to me (Xiaofeng, $1^{\text {st }}$ year graduate student).

The participants' responses to the question items regarding sense of belonging explicitly offer a distinction between belonging at MAU and belonging in the United States. The question items themselves did not make such a distinction.

I can say I belong at MAU but I don't belong in America. We don't have any relationships [in America] except with our professors (Xi, $3^{\text {rd }}$ year graduate student).

I don't know what to do [in the U.S], I never really leave campus. My professors and the people I know on campus are ok. I can do whatever I want to be ok but when I go somewhere else, I want to go with my Chinese friends. With them I feel ok and that I belong with them (Yu, $1^{\text {st }}$ year graduate student).

Data gathered regarding these Chinese students' sense of belonging, perceptions of social support and practices of self-segregation provide notable insights on international education. How these concepts intermingle and affect each other should challenge the higher education and research communities to rethink the operations and expectations of international education.

\section{Conclusion}

In this study, participants opted for self-segregation in their living arrangements, social circles and endeavors to create social support. The support gained from self-segregation remains mixed. This is regarding the differing, although predominantly positive responses, regarding international students' sense of belongingness in their academic lives, campus community, and their life in the United States.

Previous studies have contended that interaction with host nationals is beneficial to international students' well-being and academic success while studying abroad (Glass \& Westmont, 2014; Pham \& Tran, 2015; Rose-Redwood \& Rose-Redwood, 2013). It is the conclusion of this study that while there may be multi-faceted benefits to such interactions, it is by no means vital to the procurement of a sense of belonging. Considering the difficulty and frustration expressed by some of the participants in initiating and sustaining relationships with host nationals and international students of different nationalities, encouraging these relationships may be counterproductive to the development of social support and academic success. Thus, rethinking our perceptions of social support as being something only developed with host nationals, or the international community solely, may be warranted.

\section{Theoretical and Practical Implications}

As stated by Johnson et al. (2007), many American students were reluctant to befriend or engage with international students. This could be for a variety of reasons; however, one in particular is more frequently cited in the literature-the lack of intercultural competence (Johnson et al., 2007). It seems the practice of self-segregation by the Chinese community at MAU is just as much a necessity as it is a choice. Based on the results of this study, researchers may have placed too great an emphasis on this interaction, intercultural competence, inclusion, and their importance to the academic success of these Chinese students. While metrics of academic success were not collected as part of this study, the fact that many of the participants were in their second or third year of study demonstrated they were progressing in their chosen field of study. No responses or data from 
this study suggested that the lack of interaction with host nationals hindered the participants' academic performance. Yet a multitude of the data confirmed the idea that social support and sense of belonging are directly due to, not despite, the self-segregation practices by this Chinese community. These are factors which are more clearly linked with academic success. While there may be advantages and merits gained from interactions with host-nationals, the idea that these interactions are fundamentally vital, crucial, and necessary remains unfounded based on the results of this study. While university programming, events, and courses will inherently encourage intercultural exchange, the development of ICC should not be viewed as the only support mechanism for international students. Instead, administrators and educators should disregard any educational, social, or cultural stigma attached to the practice of self-segregation and support it when employed by international students.

\section{Limitations and Future Research}

This study only explored perceptions of graduate students which previous researchers have found to have lower levels of sense of belonging compared to their undergraduate counterparts (RoseRedwood \& Rose-Redwood, 2013). This was found in both international and domestic students (Rose-Redwood \& Rose-Redwood, 2013). Future studies could examine how social support behaviors of Chinese international graduate students differ from undergraduate Chinese international students. This study only captured a single experience in time. Conducting these focus groups with a research assistant, while providing insider status, could also be considered a limitation.

Lastly, the participants were graduate students from a research university in the Mid-Atlantic region of the United States. This university placed a high priority on international scholarship and enrollment. Thus, issues such as diversity, inclusivity, and social-cultural events may have been more frequent at this institution. To better understand the long-term effects of self-segregation, researchers could examine longitudinally how levels of social support and sense of belonging evolve in participants which report frequent practice of self-segregation.

\section{References}

Alexander, A., Workneh, F., Klein, M. H., \& Miller, M. H. (1976). Psychotherapy and the foreign student. In P. Pederson, W. Lonner, \& J. Draguns (Eds.), Counseling across cultures (pp. 82-97). University of Hawaii.

Allen-Embrahimian, B. (2018, March 7). China's long arm reaches to American campuses. Foreign Policy. https://foreignpolicy.com/2018/03/07/chinas-long-arm-reaches-into-american-campuses-chinese-studentsscholars-association-university-communist-party/

Behrnd, V., \& Porzelt, S. (2012). Intercultural competence and training outcomes of students with experience abroad. International Journal of Intercultural Relations, 36(2), 213-223.

Berger, J. (1997). Students' sense of community in residence halls, social integration, and first-year persistence. Journal of College Student Development, 38(5), 441-452.

Bowmann, N. (2011). Validity of college self-reported gains at diverse institutions. Educational Researcher, 40(1), 22-24.

Cohen, L., Manion, L., \& Morrison, K. (2007). Research methods in education. Routledge.

Coles, R., \& Swami, V. (2012). The sociocultural adjustment trajectory of international students and the role of university structures: A qualitative investigation. Journal of Research in International Education, 1(1), 87100.

Glass, C., \& Westmont, C. (2014). Comparative effects of belongingness on the academic success and cross-cultural interactions of domestic and international students. International Journal of Intercultural Relations, 38, 106-119. 
Guilherme, M. (2004). English as a global language and education for cosmopolitan citizenship. In A. Osler, \& H. Starkey (Eds.), Citizenship and language learning (pp. 25-42). Trentham.

Heikinheimo, P., \& Shute, J. (1986). The adaptation of foreign students: Student views and institutional implications. Journal of College Student Personnel, 27(5), 399-406.

Hiller, G., \& Wozniak, M. (2009). Developing an intercultural competence programme at an international crossborder university. Intercultural Education, 20, 113-134.

Hurtado, S., \& Carter, D. (1997). Effects of college transition and perceptions of the campus racial climate on Latino students' sense of belongingness. Sociology of Education, 70(4), 324-345.

Johnson, D., Soldner, M., Leonard, J., Alvarez, P., Kurotsuchi-Inkelas, K., Rowan-Kenyon, H., \& Longerbeam, S. (2007). Examining sense of belongingness among first-year undergraduates from different racial ethnic groups. Journal of College Student Development, 48(5), 525-542.

Leong, P. (2015). Coming to America: Assessing the patterns of acculturation, friendship formation, and the academic experiences of international students at a U.S. college. Journal of International Students, 5(4), 459-474.

Locks, A., Hurtado, S., Bowmann, N., \& Oseguera, L. (2008). Extending notions of campus climate and diversity to students' transitions to college. The Review of Higher Education, 31(3), 257-285.

Mannon, M. (2007). Student attrition and academic and social integration: Application of Tinto's model at the University of Papua New Guinea. Higher Education, 53(2), 147-165.

Morrow, J., \& Ackermann, M. (2012). Intention to persist and retention of first-year students: the importance of motivation and sense of belongingness. College Student Journal, 4(63), 483-491.

Peng, R. Z., Wu, W. P., \& Fan, W. W. (2015). A comprehensive evaluation of Chinese college students' intercultural competence. International Journal of Intercultural Relations, 47, 143-157.

Pham, L., \& Tran, L. (2015). Understanding the symbolic capital of intercultural internations: a case study of international students in Australia. International Studies in Sociology of Education, 25(3), 204-224.

Rienties, B., Beausaert, S., Grohnert, T., Niemantsverdriet, S., \& Kommers, P. (2012). Understanding academic performance of international students: the role of the ethnicity, academic and social integration. Higher Education, 63(6), 685-700.

Rose-Redwood, C. R., \& Rose-Redwood, R. S. (2013). Self-segregation or global mixing? Social interactions and the international student Experience. Journal of College Student Development, 54(4), 413-429.

Russell, J., Rosenthal, D., \& Thompson, G. (2010). The international student experience: Three styles of adaptation. Higher Education, 60(2), 235-249.

Spitzberg, B., \& Changnon, G. (2009). Conceptualizing intercultural context. In D. Deardorff (Ed.), The Sage handbook of intercultural competence (pp. 2-52). Sage.

Stahl, G. (1998). Internationaler einsatz vo fuhrungskraften [International deployment of executives]. Oldenbourg.

Trice, A. G. (2004). Mixing it up: International graduate students' social interactions with american students. Journal of College and Student Development, 45(6), 671-687.

Wilcox, P., Winn, S., \& Fyvie-Gauld, M. (2005). It was nothing to do with the university, it was just the people: The role of social support in the first-year experience of higher education. Studies in Higher Education, 18(2), 9-29.

Wu, W., Fan, P., \& Peng, R. Z. (2013). An analysis of the assemsent tools for Chinese college students' intercultural competence. Foreign Language Teaching and Research, 45(4), 581-592.

Yang, B., Teraoka, M., Eichenfield, G. A., \& Audas, M. C. (1994). Meaningful relationships between Asian international and U.S. college students: A descriptive study. College Student Journal, 28(1), 108-115.

Young, J. (2017). Confucianism and accents: Understanding the plight of the Asian international student in the U.S. Journal of International Students, 7(3), 433-448.

\section{Acknowledgement}

I would like to express my gratitude to my Research Assistant Ms. Nan Yang for her help in the collection of the data for this study. 